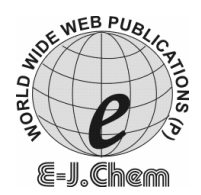

http://www.e-journals.net
ISSN: 0973-4945; CODEN ECJHAO

E-Journal of Chemistry

Vol. 5, No.4, pp. 761-769, October 2008

\title{
Ricinus Communis Pericarp Activated Carbon Used as an Adsorbent for the Removal of Ni(II) From Aqueous Solution
}

\author{
S. MADHAVAKRISHNAN ${ }^{\S}$, K.MANICKAVASAGAM ${ }^{\S}$, K.RASAPPAN, \\ P.S.SYED SHABUDEEN ${ }^{\#}$, R.VENKATESH ${ }^{\#}$, and S.PATTABHI ${ }^{\S} *$ \\ ${ }^{\S}$ Department of Environmental Science, \\ PSG College of Arts \& Science, Coimbatore - 641 014, Tamil Nadu, India. \\ Department of Civil Engineering, \\ Coimbatore Institute of Technology, Coimbatore \\ "Department of Chemistry, \\ Kumaraguru College of Technology, Coimbatore, India.
}

pattabipsges@yahoo.co.in

Received 1 February 2008; Accepted 1 April 2008

\begin{abstract}
Activated carbon prepared from Ricinus communis Pericarp was used to remove $\mathrm{Ni}$ (II) from aqueous solution by adsorption. Batch mode adsorption experiments are carried out by varying contact time, metal-ion concentration, carbon concentration and $\mathrm{pH}$ to assess kinetic and equilibrium parameters. The adsorption data were modeled by using both Langmuir and Freundlich classical adsorption isotherms. The adsorption capacity $\left(\mathrm{Q}_{0}\right)$ calculated from the Langmuir isotherm was $31.15 \mathrm{mg} / \mathrm{g}$ of activated carbon at initial $\mathrm{pH}$ of $5.0 \pm 0.2$ for the particle size $125-250 \mu \mathrm{m}$.
\end{abstract}

Keywords: Activated carbon, Metal ion, Adsorption, Kinetics, Isotherms

\section{Introduction}

The water pollution is mainly due to organics, inorganics, sediments, radioactive materials and heavy metals. Among these pollutants, the contribution of heavy metals to the environment is of major concern because of its toxicity, bioaccumulation, persistence and non-biodegradable nature. Industrial effluent containing nickel plays an important role in polluting water bodies. Additional potential sources of nickel bearing waste include ceramics, nuclear power plants, cryogenic containers, pollution abatement equipment. Nickel 
is a potent carcinogen. The contactness of nickel with skin results in painful disease, nickel itch, which is followed by sudden death. Acute poisoning of nickel causes chest pain, tightness of the chest, shortness of breath etc. The toxic nature of nickel to fish, lentil plants, crops and algae was also reported ${ }^{1}$. According to environmental protection agency (EPA), USA, the permissible limits of $\mathrm{Ni}$ (II) in wastewater is $1 \mathrm{mg} / \mathrm{L}$ and Bureau of Indian Standards is 3 $\mathrm{mg} / \mathrm{L}^{2}$. Hence, it is essential to remove Ni(II) before discharged into water bodies.

Utilizing the waste material from agriculture and industries can make treatment process economical and solve the solid waste disposal problem. The feasibility of several low cost, non-conventional adsorbents obtained from agricultural and industrial wastes was explored. Research has already been conducted on a wide variety of adsorbents. They include walnut shell, waste Turkish coffee, nut shell exhausted coffee ${ }^{3}$, saw dust ${ }^{4}$, rice bran, soya bean and cotton seed hull ${ }^{5}$ have been investigated to remove nickel(II) from wastewater. The present study deals with the use of activated carbon prepared from Ricinus communis Pericarp as an adsorbent for the removal of $\mathrm{Ni}$ (II) from aqueous solution. The main aim of this work was to evaluate the feasibility of using Ricinus communis Pericarp carbon for Ni(II) removal.

\section{Experimental}

\section{Adsorbent}

In the present study, Pericarp of Ricinus communis used for the preparation of activated carbon. The dried Pericarp was allowed to chemical activation, by the addition of $50 \%$ sulfuric acid with constant stirring (w/v). The charred material was kept in hot air oven at $100 \pm 5^{\circ} \mathrm{C}$ for $12 \mathrm{~h}$. This was washed with double distilled water and this was soaked in $10 \%$ sodium bicarbonate solution and allowed to stand overnight to remove the residual acid from pores of the carbon. The material was washed with distilled water, until the $\mathrm{pH}$ of the adsorbent reached $7 \pm 0.2$. Then it was dried in a hot air oven at $100 \pm 5^{\circ} \mathrm{C}$ for $12 \mathrm{~h}$. The dried material was ground and sieved to get the particle size of $125-250 \mu \mathrm{m}$. The sieved adsorbent was stored in an airtight container for further experiments. All the chemicals used were of analytical reagent grade obtained from B.D.H and E.Merck. Double distilled water was used for all the experimental studies.

\section{Adsorbate}

$\mathrm{Ni}(\mathrm{II})$ stock solution $(1000 \mathrm{mg} / \mathrm{L})$ was prepared in double distilled water using nickel sulphate. The working solution was obtained by diluting the stock solution in distilled water.

\section{Batch mode adsorption studies}

The working solution of $10,20,30,40 \mathrm{mg} / \mathrm{L}$ of Ni(II) was prepared from stock solution. Batch mode adsorption studies were carried out with $50 \mathrm{mg}$ of the adsorbent and $50 \mathrm{~mL}$ of Ni(II) solution of desired concentration at a $\mathrm{pH}$ of $5.0 \pm 0.2$, agitated at $120 \mathrm{rpm}$ in a mechanical shaker at room temperature. The adsorbate solution was separated from the adsorbent by centrifugation at $3000 \mathrm{rpm}$ and estimated spectrophotometrically at $470 \mathrm{~nm}$ using dimethylglyoxime reagent ${ }^{6}$. The effect of carbon dosage on percent removal of $\mathrm{Ni}$ (II) was studied with solutions of $30 \mathrm{mg} / \mathrm{L}$ for particle size $125-250 \mu \mathrm{m}$. Effect of $\mathrm{pH}$ on $\mathrm{Ni}$ (II) removal was studied for metal ion concentration of 20 and $40 \mathrm{mg} / \mathrm{L}$ using $50 \mathrm{mg}$ of carbon dosage.Langmuir isotherm study was carried out with different initial concentration of $\mathrm{Ni}$ (II) from 5 to $40 \mathrm{mg} / \mathrm{L}$, while maintaining the adsorbent dose at $50 \mathrm{mg} / 50 \mathrm{~mL}$. Desorption studies was carried out to confirm the adsorption mechanism proposed above and to recover the metals from the adsorbent using 0.025 to $0.350 \mathrm{M}$ hydrochloric acid. 


\section{Results and Discussion}

\section{Adsorbent characterization}

Characteristics of activated carbon prepared from Ricinus communis Pericarp are presented in Table 1. The determined surface area of Ricinus communis Pericarp activated carbon (RCP) was $495 \mathrm{~m}^{2} / \mathrm{g}$ and is comparable to various low cost adsorbents namely, peanut hull carbon $^{7}\left(208 \mathrm{~m}^{2} / \mathrm{g}\right)$, eichhornia ${ }^{8}\left(200 \mathrm{~m}^{2} / \mathrm{g}\right)$, cassava $\left(200 \mathrm{~m}^{2} / \mathrm{g}\right)$ and coconut tree saw dust carbon $^{10}\left(325 \mathrm{~m}^{2} / \mathrm{g}\right)$. The moisture content of the carbon was found to be $2.50 \%$ (Table 1 ). This would not influence the adsorptive power of activated carbon. It was then observed from the literature that if the moisture content of the adsorbent is more, it will dilute the action of activated carbon and it necessitates utilizing some extra load of carbon ${ }^{11}$. The iodine number and decolorizing power were $468 \mathrm{~g} / \mathrm{g}$ and $21.0 \mathrm{mg} / \mathrm{g}$ respectively which indicates that the carbon prepared by acid activation method has good adsorption capacity and it can be considered for adsorption of organic dyes. The surface morphology of activated carbon (RCP) was visualized via scanning electron microscopy (SEM), the corresponding SEM micrographs being obtained using a JSM-840 JEOL microscope of JEOL Techniques LTD, Japan at 2000x magnification (Figure. 1). Examination of SEM micrographs of the RCP particles showed rough areas of the surface of the carbon and the microspores were identifiable. The activation process of RCP by adopting sulphuric acid treatment leads to corrode the surface of carbonaceous material and introduce micro, macro and mesopores.

Table 1. Characteristics of activated carbon

\begin{tabular}{lc}
\hline \multicolumn{1}{c}{ Parameters } & Value \\
\hline $\mathrm{pH} 1 \%$ solution & 6.90 \\
Moisture content, \% & 2.50 \\
Ash content, \% & 6.50 \\
Decolorizing power, mg /g & 21.00 \\
Ion - exchange capacity, equi g & 0.80 \\
Determination of surface area, ${ }^{2} / \mathrm{g}$ & 495 \\
Bulk density, gm /L & 0.46 \\
Porosity, \% & 68.27 \\
Specific gravity & 1.46 \\
Particle size, $\mu \mathrm{m}$ & $125-250$ \\
Iodine number, mg/g & 468 \\
Yield, \% & 70 \\
Calcium, mg/g & 20.0 \\
Sodium, mg / g & 28.8 \\
Potassium, mg /g & 2.3 \\
Water - soluble matter, \% & 1.29 \\
HCl soluble matter, $0.25 \mathrm{~N}, \%$ & 2.45 \\
\hline
\end{tabular}

\section{Effect of agitation time on Nickel(II) adsorption}

The effect of agitation time on the percent removal of $\mathrm{Ni}$ (II) by RCP carbon is shown in Figure 2. The percent removal increases with increase in agitation time and attains equilibrium within $70 \mathrm{mts}$ for all the concentrations studied (10 to $40 \mathrm{mg} / \mathrm{L}$ ). The curves were single, smooth and continuous till the saturation of $\mathrm{Ni}$ (II) on activated carbon surface. 


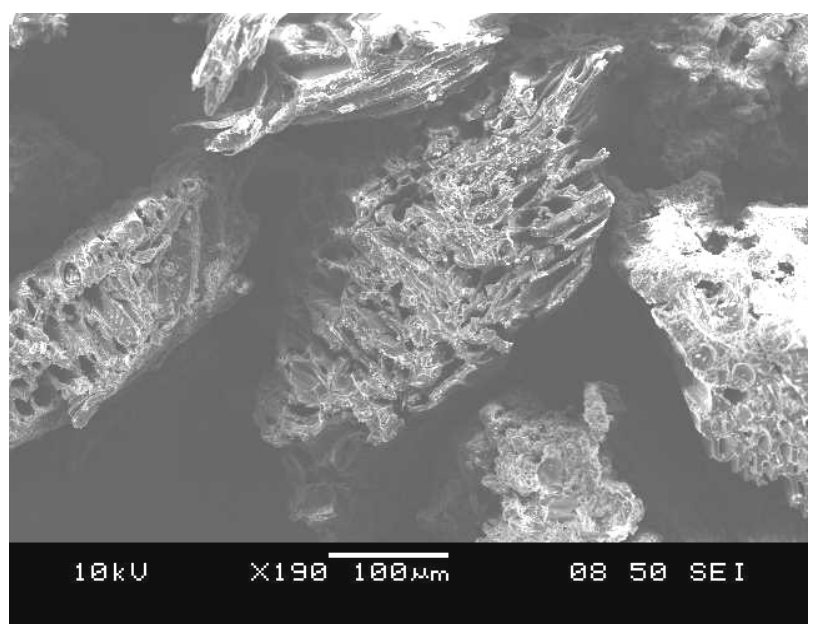

Figure 1. SEM Photograph of the RCP carbon

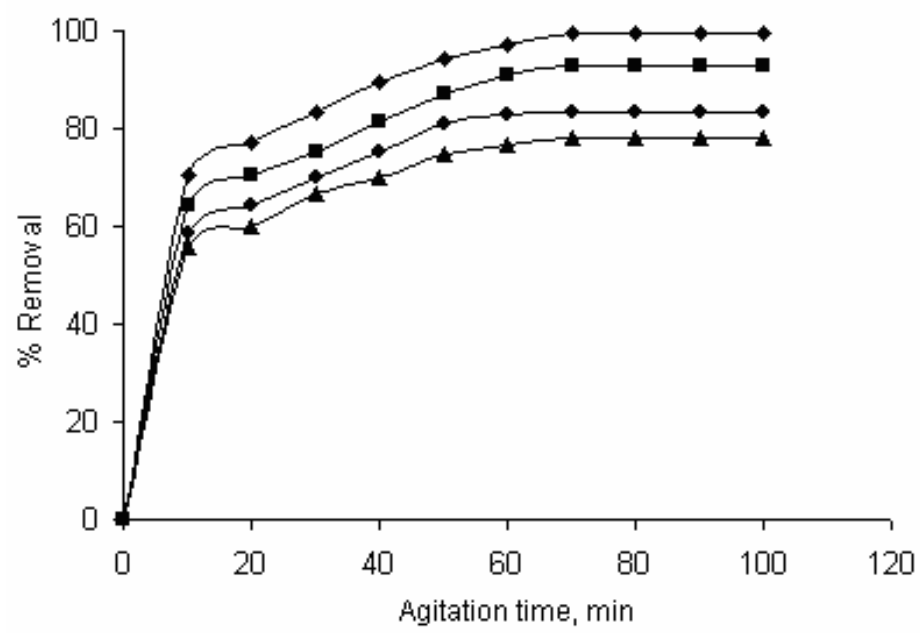

$\multimap-10 \mathrm{mg} / \mathrm{L} \rightarrow-20 \mathrm{mg} / \mathrm{L} \rightarrow 30 \mathrm{mg} / \mathrm{L} \rightarrow 40 \mathrm{mg} / \mathrm{L}$

Figure 2. Effect of agitation time and initial $\mathrm{Ni}(\mathrm{II})$ concentration on $\mathrm{Ni}(\mathrm{II})$ adsorption

\section{Adsorption kinetics}

The adsorption kinetics of $\mathrm{Ni}$ (II) on adsorbent follows first order rate expression given by Lagergren $^{12}$.

$$
\log _{10}\left(\mathrm{q}_{\mathrm{e}}-\mathrm{q}\right)=\log _{10} \mathrm{q}_{\mathrm{e}}-\mathrm{K}_{\mathrm{ad}} \mathrm{t} / 2.303
$$

Where, $K_{a d}(1 / \mathrm{min})$ is the rate constant of adsorbent, $q$ and $q_{e}$ are the amount of $\mathrm{Ni}(\mathrm{II})$ adsorbed $(\mathrm{mg} / \mathrm{g})$ at time $\mathrm{t}(\mathrm{min})$ and equilibrium time. Linear plots of $\log { }_{10}\left(\mathrm{q}_{\mathrm{e}}-\mathrm{q}\right)$ versus $\mathrm{t}$ (Figure 3) shows the applicability of above equation. The $\mathrm{K}_{\mathrm{ad}}$ values for different $\mathrm{Ni}$ (II) ion concentrations of $10,20,30$ and $40 \mathrm{mg} / \mathrm{L}$ calculated from the slope of the plots were $0.0504,0.0511,0.0732$ and $0.05641 / \mathrm{min}$ respectively. 


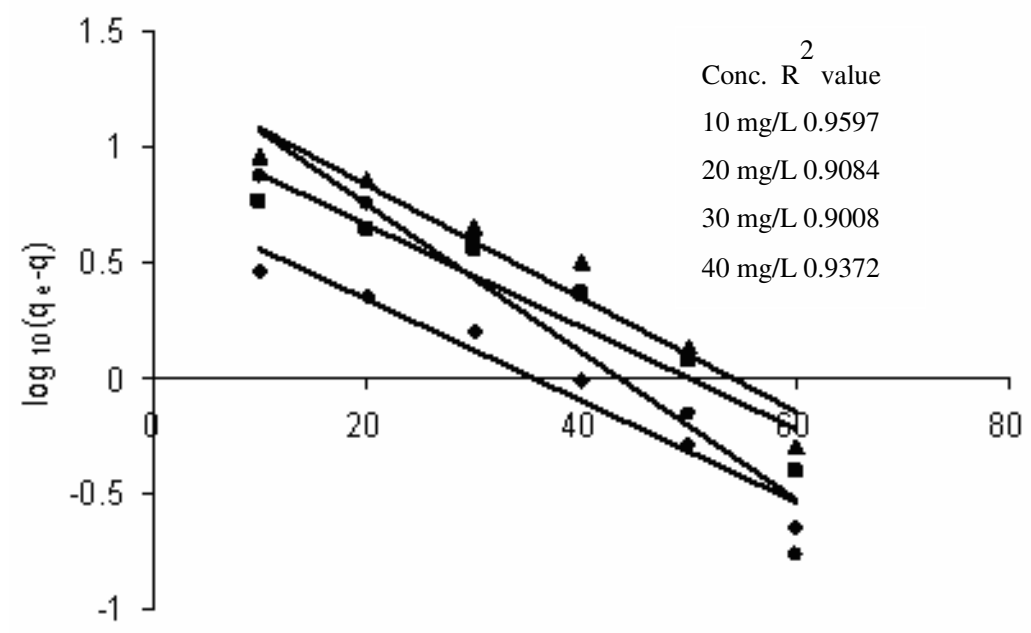

Agitation time, min

$+10 \mathrm{mg} / \mathrm{L}=20 \mathrm{mg} / \mathrm{L} \cdot 30 \mathrm{mg} / \mathrm{L}+40 \mathrm{mg} / \mathrm{L}$

Figure 3. Lagergren plots for Ni(II) adsorption

\section{Effect of adsorbent dosage on Nickel(II) adsorption}

The effect of carbon dosage on percent removal of $\mathrm{Ni}$ (II) is shown in Figure 4. When the carbon dosage increases, the percent removal also increases. It was found that for the removal of $\mathrm{Ni}(\mathrm{II})$ of $30 \mathrm{mg} / \mathrm{L}$, the maximum adsorbent dosage of $80 \mathrm{mg} / 50 \mathrm{~mL}$ was required. Increasing adsorbent dosage increases the removal because of availability of more surface area and functional group.

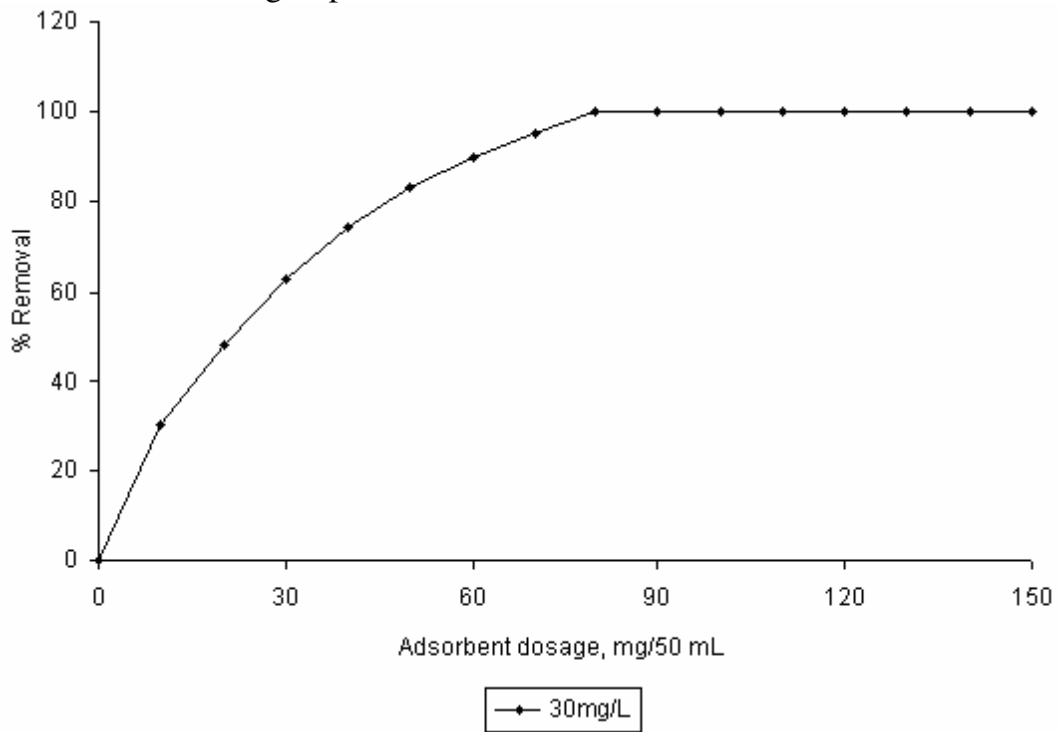

Figure 4. Effect of carbon dosage on $\mathrm{Ni}(\mathrm{II})$ adsorption 


\section{Adsorption isotherms}

The Langmuir isotherm can be applied for adsorption equilibrium of $\mathrm{Ni}(\mathrm{II})$ onto RCP carbon $^{13}$

$$
\mathrm{C}_{\mathrm{e}} / \mathrm{q}_{\mathrm{e}}=1 / \mathrm{Q}_{\mathrm{ob}}+\mathrm{C}_{\mathrm{c}} / \mathrm{Q}_{\mathrm{o}}
$$

Where, $\mathrm{C}_{\mathrm{e}}$ is the equilibrium concentration ( $\left.\mathrm{mg} / \mathrm{L}\right), \mathrm{q}_{\mathrm{e}}$ is the amount of $\mathrm{Ni}(\mathrm{II})$ adsorbed $(\mathrm{mg} / \mathrm{g})$, $\mathrm{Q}_{\mathrm{o}}$ and $\mathrm{b}$ are Langmuir constants related to adsorption capacity and energy of adsorption respectively. The linear plot of $\mathrm{C}_{\mathrm{e}} / \mathrm{q}_{\mathrm{e}}$ versus $\mathrm{C}_{\mathrm{e}}$ (Figure 5) shows that the adsorption follows Langmuir isotherm where $\mathrm{Q}_{0}=31.15 \mathrm{mg} / \mathrm{g}$ and $\mathrm{b}=1.7262$ for $5-40 \mathrm{mg} / \mathrm{L}$ concentration. Langmuir isotherm can be expressed in terms of dimensionless separation factor of equilibrium parameter

$$
\mathrm{R}_{\mathrm{L}}=\left(1 / 1+\mathrm{bC} \mathrm{C}_{\mathrm{o}}\right. \text {. }
$$

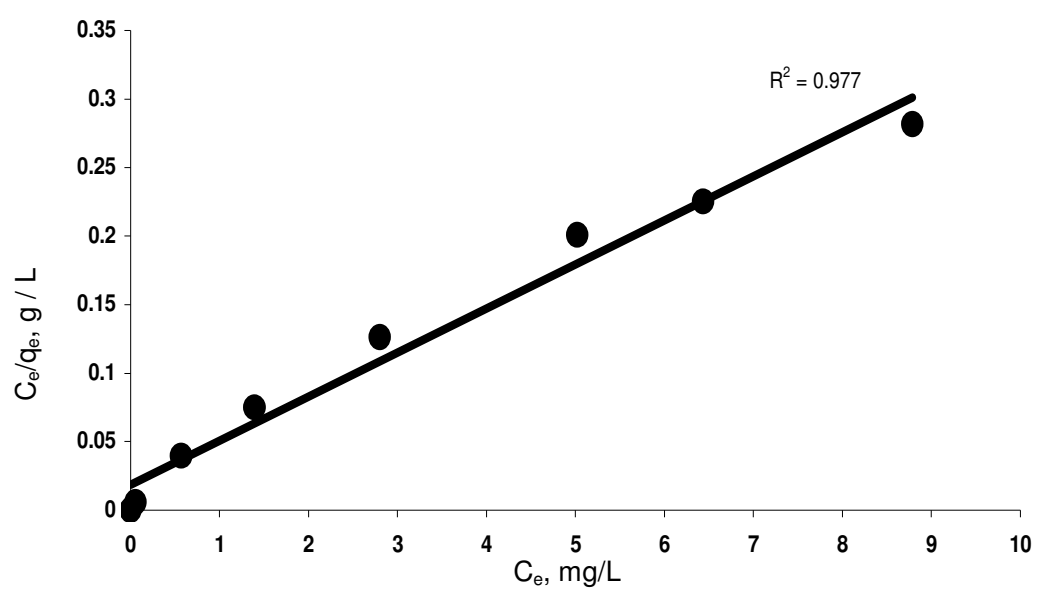

Figure 5. Langmuir plot for $\mathrm{Ni}(\mathrm{II})$ adsorption

Where, $\mathrm{C}_{\mathrm{o}}$ is the initial $\mathrm{Ni}(\mathrm{II})$ concentration $(\mathrm{mg} / \mathrm{L})$ and $\mathrm{b}$ is the Langmuir constant $\left(\mathrm{L} / \mathrm{mg}\right.$ ). $\mathrm{R}_{\mathrm{L}}$ values for different $\mathrm{Ni}(\mathrm{II})$ ion concentration (Table 2) was found to be between 0 to 1 indicate favourable adsorption of $\mathrm{Ni}(\mathrm{II})$ on to RCP carbon. The linear form of Freundlich equation can be given by, $\log _{10}(\mathrm{X} / \mathrm{m})=\log _{10} \mathrm{~K}_{\mathrm{f}}+1 / \mathrm{n} \log _{10} \mathrm{C}_{\mathrm{e}}$

Table 2. Analysis of langmuir isotherm for $\mathrm{Ni}(\mathrm{II})$ adsorption

\begin{tabular}{ccccc}
\hline S. No. & $\begin{array}{c}\text { Initial Ni(II) Concentration, } \\
\mathrm{mg} / \mathrm{L}\end{array}$ & $\mathrm{R}_{\mathrm{L}}$ & $\mathrm{Q}_{0,} \mathrm{mg} / \mathrm{g}$ & $\mathrm{B}, \mathrm{L} / \mathrm{mg}$ \\
\hline 1 & 5 & 0.1038 & & \\
2 & 10 & 0.0547 & & \\
3 & 15 & 0.0371 & & \\
4 & 20 & 0.0281 & 31.15 & 1.7262 \\
5 & 25 & 0.0226 & & \\
6 & 30 & 0.0189 & & \\
7 & 35 & 0.0162 & & \\
8 & 40 & 0.0142 & \\
\hline
\end{tabular}

Where, $\mathrm{X}$ is the amount of $\mathrm{Ni}(\mathrm{II})$ adsorbed at equilibrium $(\mathrm{mg}), \mathrm{m}$ is the weight of adsorbent used (mg), $C_{e}$ is the equilibrium concentration of $\mathrm{Ni}(\mathrm{II})$ in solution $(\mathrm{mg} / \mathrm{L}), \mathrm{K}_{\mathrm{f}} \& \mathrm{n}$ are constants. Linear plot of $\log _{10} \mathrm{x} / \mathrm{m}$ versus $\log _{10} \mathrm{C}_{\mathrm{e}}$ show that the adsorption follows Freundlich isotherm (Figure 6). The Freundlich constants $\mathrm{K}_{\mathrm{f}}$ and $\mathrm{n}$ are found to be 16.850 and 3.561 respectively for $5-40 \mathrm{mg} / \mathrm{L}$ concentration. 


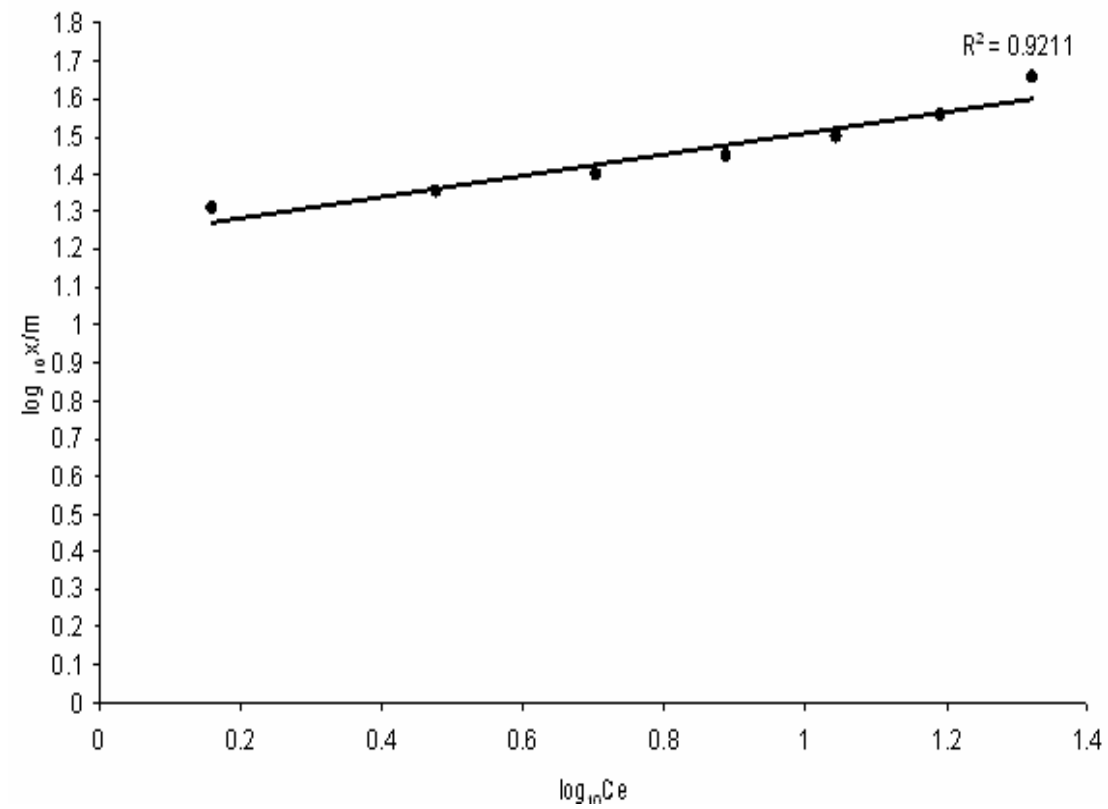

Figure 6. Freundlich plot for Ni(II) adsorption

\section{Effect of pH on Nickel(II) adsorption}

The effect of $\mathrm{pH}$ from 2.0 to 10.0 was studied to remove nickel(ii) ions from the aqueous solution with adsorbent (Figure. 7). The precipitation was observed from the results at $\mathrm{pH}$ 6.0 onwards and the intensity of precipitation increases with the increase in $\mathrm{pH}$ from 6.0 to 10.0. Similar observations were reported for coir pith carbon ${ }^{14}$.The removal of metal ions increases with increase in $\mathrm{pH}$ from 6.0 to 10.0 even without adsorbent, this is may be due to the formation of metal hydroxide precipitation.

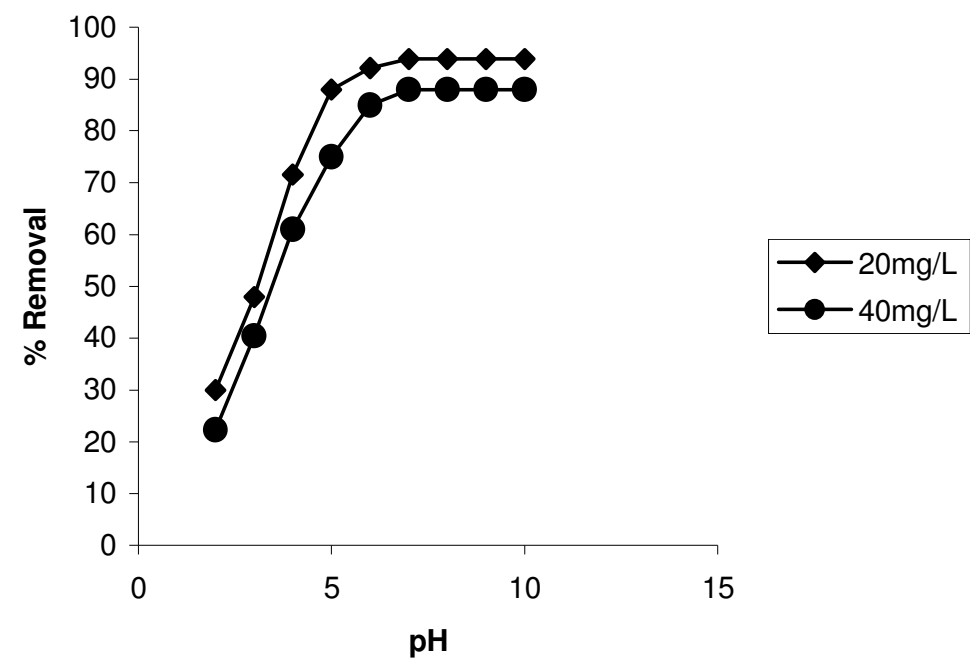

Figure 7. Effect of $\mathrm{pH}$ on $\mathrm{Ni}(\mathrm{II})$ adsorption 


\section{Desorption studies}

Desorption studies was carried out to confirm the adsorption mechanism proposed above and to recover the metals from the adsorbent. The quantitative recovery of metal ion indicated that regeneration of carbon was possible. This is further evidence that ion exchange is involved in the adsorption mechanism. Desorption was carried at different concentration of hydrochloric acid $(0.025-0.350 \mathrm{M})$. The results are shown in Figure 8 . Maximum desorption occurs at the strength of $0.325 \mathrm{M}$.

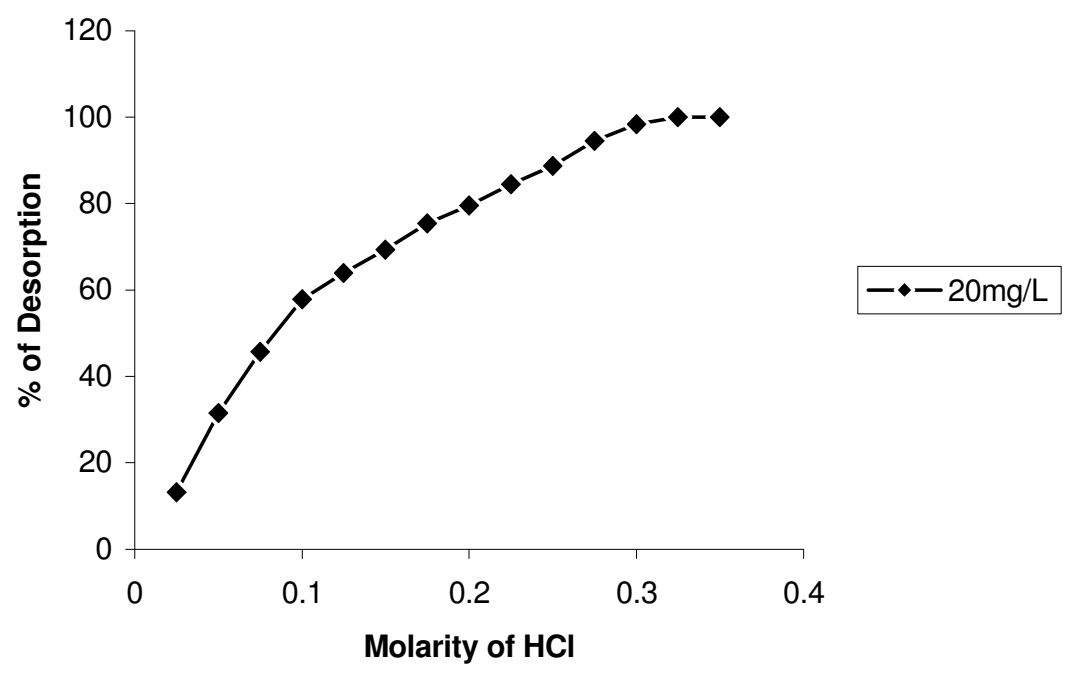

\section{Conclusion}

Figure 8. Desorption of Ni(II) ions from RCP carbon

The current investigation shows that Ricinus communis Pericarp carbon is very effective adsorbent in removal of $\mathrm{Ni}$ (II) ions from aqueous solution. Increase in adsorbent dosage and agitation time increases $\mathrm{Ni}$ (II) ion removal at the optimum $\mathrm{pH}$ of $5 \pm 0.2$. The adsorption followed both Langmuir and Freundlich isotherm models. The desorption studies reveals that recovery of $\mathrm{Ni}(\mathrm{II})$ ions from adsorbent is possible.

\section{References}

1. David P, Elsevier, Amsterdam, 1977, 143.

2. Indian Standards Institution, IS, 2490, 1981.

3. Orhaon Y and Buyukgugor H, Sci Technol., 1993, 28, 247-255.

4. Zarraa M A, Adsorption Sci Technol., 1995, 12,129-138

5. Marshall W E and Johns M N, J Chem Technol Biotechnol., 1996. 66, 192-198

6. Allen H E and Minear R A, Metallic ions In: Examination of water for pollution control - physico chemical and radiological examination, Ed. M. J. Success, Oxford, 1982. 2, 41.

7. Periasamy K and Namasivayam C, Chemosphere, 1996, 32, 769-789.

8. Shekinah P, Kadirvelu K, Kanmani P, Senthilkumar P, Subburam V, J Chem Technol Biotechnol., 2002, 77, 458-463.

9. Rajeshwari S, Sivakumar S, Senthilkumar P and Subburam V, Biores Technol., 2001, 81, 1-3. 
10. Selvi K, Kadirvelu K and Pattabhi S, Biores Technol., 2001, 79, 87-89.

11. Sugunadevi S R, Sathishkumar M, Shanthi K, Kadirvelu K and Pattabhi S, Indian J Environ Protection, 2002, 22, 500-505.

12. Hawash S, Abd H E I,Geundi M S, Wassar M M and Farash J Y, Adv Sci Technol.,1993, 1, 231-243.

13. Langmuir I, J Am Chem Soc, 1918, 40, 136.

14. Kadirvelu K and Namasivayam C, Environ Technol., 2000, 21, 1091-1097. 


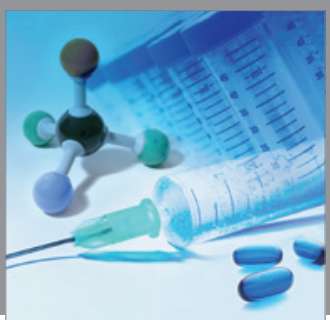

International Journal of

Medicinal Chemistry

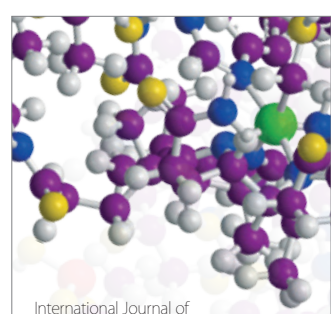

Carbohydrate Chemistry

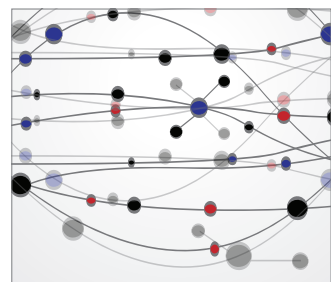

The Scientific World Journal
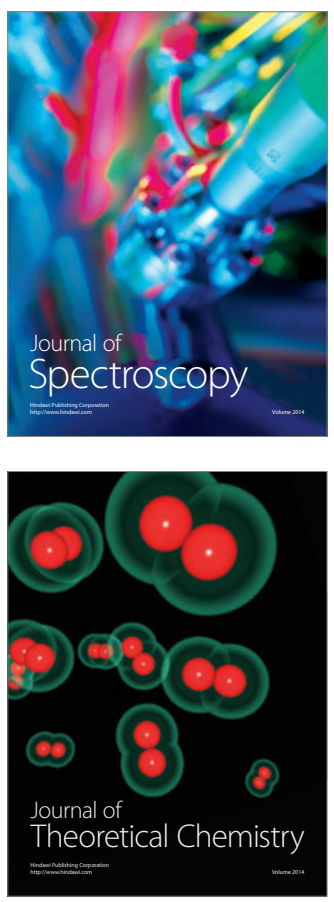
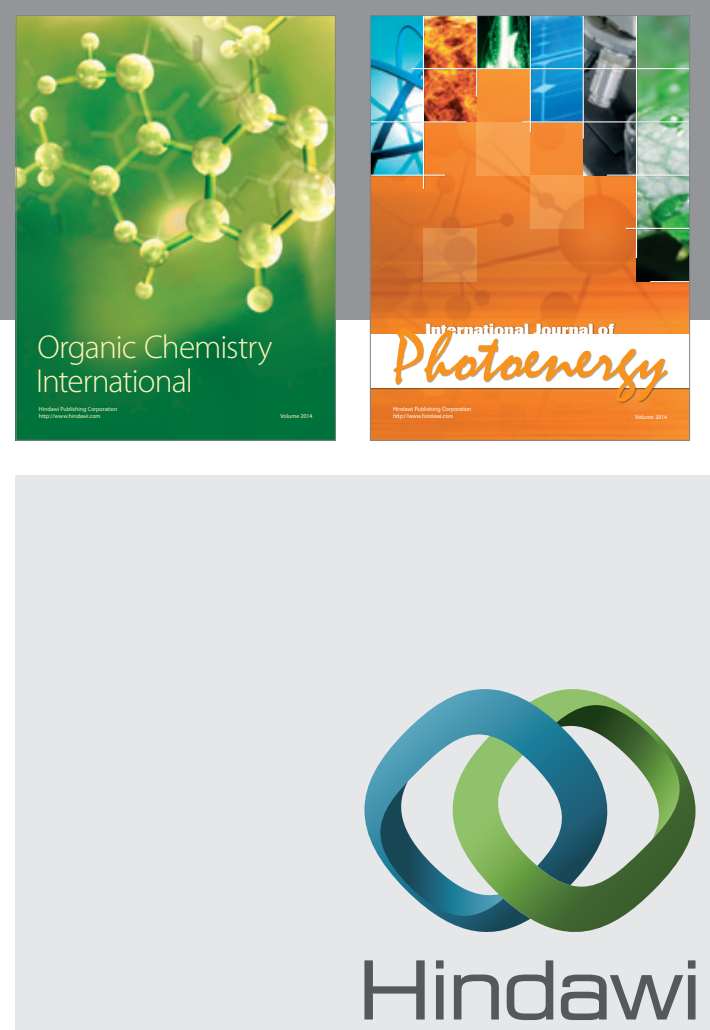

Submit your manuscripts at

http://www.hindawi.com
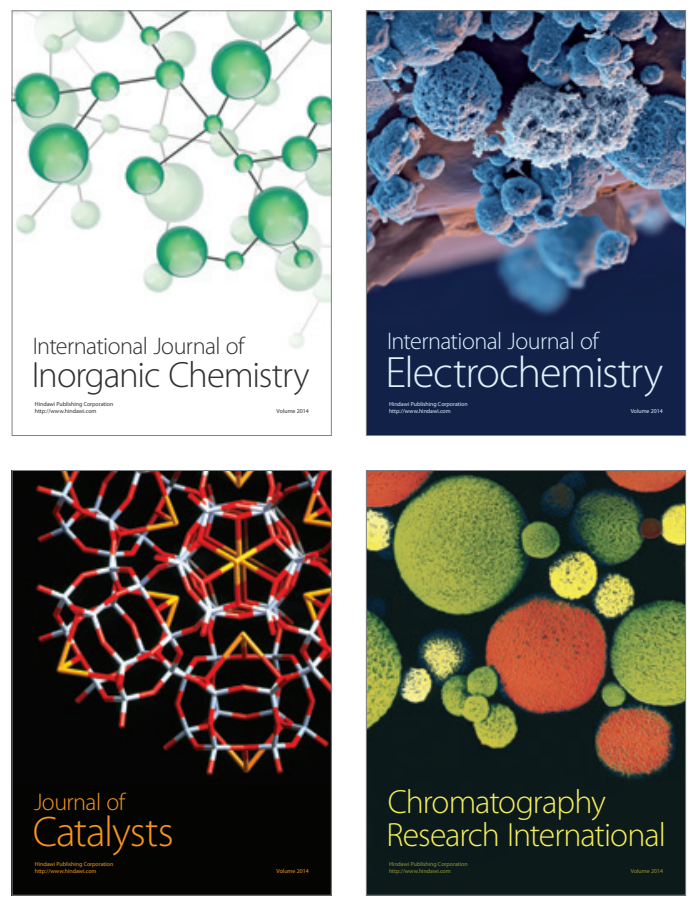
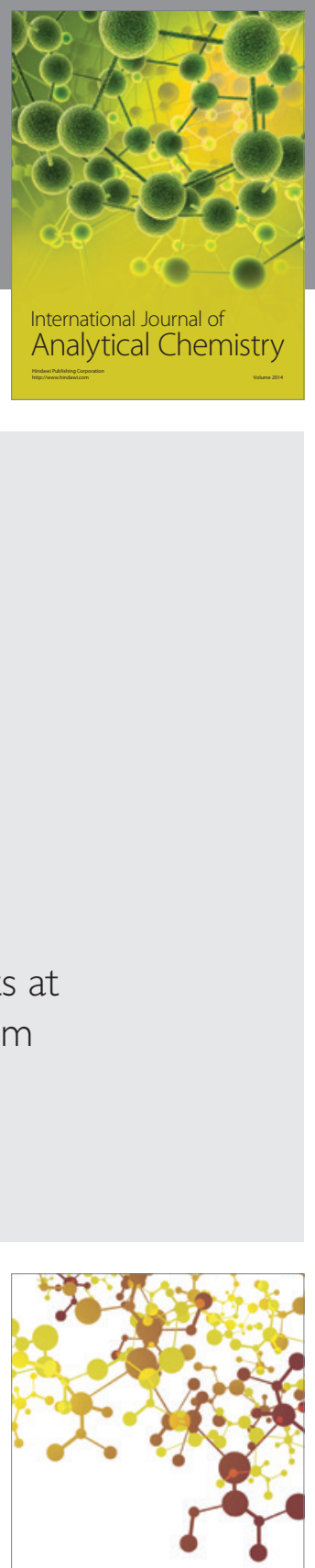

Journal of

Applied Chemistry
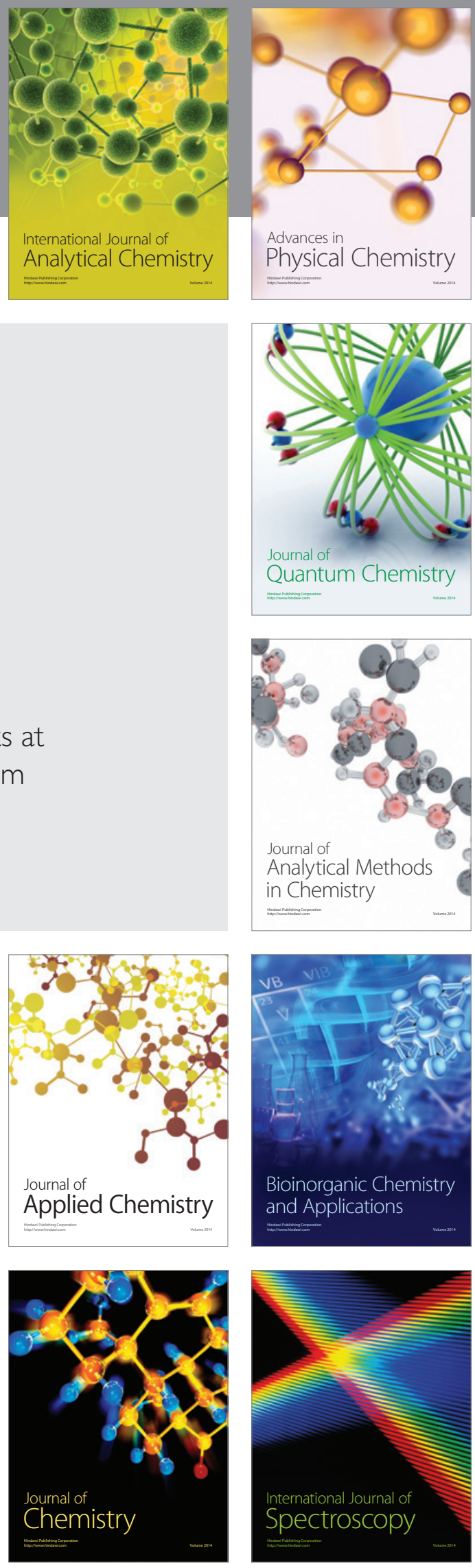